\title{
THE REASONS OF UNSATISFACTORY RESULTS OF EXTRACORPOREAL SHOCK WAVE LITHOTRIPSY IN PATIENTS WITH URETEROLITHIASIS
}

\author{
Oleksandr Vozianov \\ Department of Endourology and Lithotripsy \\ State Institution «Institute of Urology of National Academy of Medical Sciences of Ukraine» \\ 9-a Vladimira Vinnichenko str., Kyiv, Ukraine, 04053 \\ dr.vozianov.uro@gmail.com
}

\begin{abstract}
The article dedicate to the problem of failure of extracorporeal shockwave lithotripsy in patients with ureterolithiasis and reveal the changes which appear in the ureter in the location of the stone.

The aim. Analysis of the results of treatment in patients, suffering ureteric stones, using the ureterolithotripsy procedure after failure extracorporeal shockwave lithotripsy.

Materials and methods. In 137 patients with ureteric stones, whom ureterolithotripsy procedure after failure extracorporeal shockwave lithotripsy was conducted, the symptoms of the disease, the diagnostic methods value, efficacy of surgical treatment and reasons of the failure of previous method of treatment were analyzed.

Results. In 135 patients endoscopic removal of stones has been succeeded, in 2 patients because of total obliteration of the ureter, uretero-ureteral anastomosis has been performed. If the symptoms, with are characteristic of ureterolithiasis, persists up to one week stones don't cause significant macroscopic changes to the ureter wall. If the stone persists in the ureter longer than a week we identified local appearing of oedema. Long-term (more than two months) ureteric stone persistence increase the risk of intramucosal «ingrowth» of the calculi greatly.

Conclusion. The URS and ESWL are high effective and minimal invasive methods of surgical intervention for patients with ureterolithiasis, guaranteeing high level of postoperative «stone free rate». Prolongation of the stone insertion time in the ureter causes the ureteric wall changes, complicating performance of minimal invasive interventions (ureterolithotripsy and extracorporeal shock-wave lithotripsy) and reduce its efficacy.
\end{abstract}

Keywords: urology, disease, ureterolithiasis, ureterolithotripsy, extracorporeal shock wave lithotripsy, low-invasive surgery, endoscopy, diagnostics, treatment, prophylactics.

DOI: $10.21303 / 2504-5679.2021 .001797$

\section{Introduction}

Urolithiasis is a term used to describe stones that are formed in the urinary tract. It involves the formation of calculus in the urinary system, mainly in the kidneys which can move through the urinary system causing pain (renal colic), blood in urine, fever and inflammation. The stone forming risks depends on geographic, ethnic, alimentary and genetic factors. The prevalence rates for urinary stones vary from $1 \%$ to $9 \%$ in European countries, which use to be known as countries with high standard of life and up to $13 \%$ in USA [1]. Ureterolithiasis is a high recurrence risk disease, $40 \%$ of patients recur within 5 years and $75 \%$ recur within 20 years [2].

Diagnostic visualization of kidney and ureteral stones is primary done by ultrasound (US) examination, which is safe, inexpensive and real-time. It can identify stones located in the kidney calyces, pelvis, pyeloureteric junction, all localisation of the ureter, as well as the upper urinary tract dilatation. Ultrasound has a sensitivity of $45 \%$, specificity of $94 \%$ for ureteral stones and a sensitivity of $45 \%$ and specificity of $88 \%$ for renal stones [3, 4]. In addition, kidney, ureter and bladder $\mathrm{X}$-ray (KUB) is often used as common method of diagnostic. The sensitivity and specificity of KUB is $44-77 \%$ [5]. Non-contrast CT can determine stone quantity, localization, size, density, skin-tostone distance, surrounding anatomy and urinary collecting system anatomy [6]. CT for urolithiasis shows sensitivity of $93.1 \%$ and a specificity of $96.6 \%$ for stones bigger than $3 \mathrm{~mm}[7,8]$.

The European Association of Urology Guidelines define extracorporeal shockwave lithotripsy (ESWL) and ureterolithotripsy (URS) as the first-line methods of treatment for ureteral stones 
up to $2 \mathrm{~cm}[9,10]$. Stone-free rate in the early postoperative period after URS and ESWL depends on many factors and can show significant difference in one trial (84\% to 62.5\%) [11] and practically no difference between methods in other (97.5\% to $92.5 \%$ ) [12]. Also, antegrade percutaneous nephroureterolithotomy (antegrade - PCNUL) and laparoscopic/open surgery ureterolithotomy can be used for long-term «impacted» stones and ureteral calculi bigger than $2 \mathrm{~cm}[13,14]$. These interventions show high stone-free rate [15, 16] however, are more traumatic and have longer rehabilitation term [17].

The aim of the research: to study the factors that may affect the effectiveness of treatment in patients, suffering ureteric stones, using the ureterolithotripsy procedure after failure extracorporeal shockwave lithotripsy.

\section{Materials and methods}

Annually in the clinical departments of state institution «Institute of Urology of National Academy of Medical Sciences of Ukraine» more than 650 patients with ureterolithiasis are treated by ESWL.

In the period from 2013 to 2016 (4 year), more than 2600 patients with ureteral stones were affected by ESWL and only 137 cases were ineffective (did not achieve fragmentation, complete stone elimination or had complications) and ureteroscopy in this group was performed.

This study was approved by the ethics commission of State Institution «Institute of urology of National academy of medical sciences» (protocol No. 10 on October 06, 2017).

This study is retrospective; was conducted in accordance with the Declaration of Helsinki and informed consent was obtained from all patients (before performing treatment).

Among 137 patients there were $75(54.74 \%)$ males and $62(45.26 \%)$ females aged 26-77 yo (53.83 \pm 11.83 yo). Calculi were localized in the upper third part of ureter in $76(55.47 \%)$ pts, in the middle part - in $15(10.95 \%)$ pts and in the lower part - in 46 (33.58 \%) pts. Calculi were present in the left ureter in 67 (48.91\%) cases and in the right ureter - in 70 (51.09\%) cases.

Preoperative standard examination of patients with ureteral stones included anamnestic, clinical, biochemical urine and blood tests, test of the coagulation system, blood group and $\mathrm{Rh}$ factor, electrocardiogram, ultrasound (US) examination of urine tract system, X-ray of kidney, ureter an bladder, non-contrast CT scan of abdomen and pelvis if needed.

All patients underwent ESWL by standard technique, using a Siemens Modularis Uro lithotripter. The patient position on the operating table was supine. Stone has being visualized with both fluoroscopy and ultrasound control. Frequency was 90 shock impulse/min. Number of impulse was from 1200 to 3000, energy - from 1.2 to 3.5. The patients were given intravenous aneastesia (fentanil $50 \mathrm{mcg}$ ). Next ESWL session were done if there was fragmentation of the stone, moving of the fragments distally in the ureter seen on X-Ray or US and no complications. Patients we did not achieve fragmentation, complete stone elimination or had complications ureteroscopy was performed.

All URS were done under general anesthesia. Initially cystoscopy and ureteroscopy were performed. We used 8 Fr/9.8 Fr semirigid ureteroscope (Richard Wolf Germany) after introduction of guidewire ( 0.032 inch, Cook roadrunner guidewire, USA) into the ureter under fluoroscopic control. German Holmium laser Liza Laser Sphinx30 was used to break the stone. Dormia basket (Cook 3.5 Fr) and graspers were used to remove the fragments. If patients had risks of obstruction of upper urinary tract or postoperative inflammation and pyelonephritis the kidney was drained by ureteral stent 6-24/26 Fr. All the patients were given intravenous antibiotics ( $3^{\text {rd }}$ generation cephalosporins) for prophylaxis one hour preoperatively and then continued for the next days staying in hospital. Ureteral stent was removed after 2-3 weeks.

In some cases (5 patients) stones where removed by antegrate - PCNUL and in 2 cases with total obstruction of the ureteral lumen open surgery uretero-ureteral anastomoses were performed.

Statistical processing of information was performed using sample mean and standard deviation $(\mathrm{M} \pm \mathrm{m})$ for characterizing the indicators in the group.

\section{Results}

According to the results of studies of 137 patients, we identified that the ratio of people with normal weight to overweight people is 1:3.89 (Table 1). 
Table 1

Distribution of patients according to age and body mass index

\begin{tabular}{|c|c|c|c|c|c|c|c|}
\hline \multirow{3}{*}{ Age, (years) } & \multicolumn{6}{|c|}{ Body mass index (BMI) } & \multirow{3}{*}{ Total, (\%) } \\
\hline & $<18.5$ & $18.5-24.9$ & $25.0-29.9$ & $30.0-34.9$ & $35.0-39.9$ & $\geq 40$ & \\
\hline & $n(\%)$ & $n(\%)$ & $n(\%)$ & $n(\%)$ & $n(\%)$ & $n(\%)$ & \\
\hline $18-35$ & $0(0.0)$ & $4(33.3)$ & $7(58.3)$ & $1(8.3)$ & $0(0.0)$ & $0(0.0)$ & $12(8.8)$ \\
\hline $36-59$ & $1(1.4)$ & $12(16.4)$ & $25(34.2)$ & $24(32.9)$ & $10(13.7)$ & $1(1.4)$ & $73(53.3)$ \\
\hline$\geq 60$ & $0(0.0)$ & $11(21.2)$ & $21(40.4)$ & $14(26.9)$ & $5(9.6)$ & $1(1.9)$ & $52(38.0)$ \\
\hline Total, (\%) & $1(0.7)$ & $27(19.7)$ & $53(38.7)$ & $39(28.5)$ & $15(10.9)$ & $2(1.5)$ & $137(100.0)$ \\
\hline
\end{tabular}

During hospitalization patients suffered from flank pain in 124 (90.51) cases, renal colic $29(21.17 \%)$, haematuria - $85(62.04 \%)$, dysuria - $28(20.44 \%)$, fever (temperature higher than $\left.37.5^{\circ} \mathrm{C}\right)-45(32.85 \%) .8$ patients $(5.84 \%)$ had no complaints.

Leukocytes in the blood more $9.0 \times 109 / 1$ had 34 (24.82\%) people. Erythrocytes in the blood were $4.58 \pm 0.33 \times 10^{12} / 1$ had $110(80.29 \%)$ patients; in $27(19.71 \%)$ I-II stage of anaemia has been indicated. The level of creatinine was increased in 48 (35.04\%).

In all 137 cases, stones in the ureter were visualized during ultrasound examination. The dilatation of the upper urinary tract caused by obstruction of the ureter by the stone had $130(94.89 \%)$ people.

Radiopaque stones were identified in 129 (94.16\%) patients.

The stone size was from 6 to $19 \mathrm{~mm}(11.5 \pm 2.5 \mathrm{~mm})$.

The duration of common symptoms associated with ureterolithisis till first session of ESWL was in the term $\leq 7$ days in $12(8.76 \%)$ cases, 8-14 days - 30 (21.90\%), 15-29 days - 34 (24.82\%), $30-59$ days $-31(22.63 \%), \geq 60$ days $-30(21.90 \%)$.

The obtained results show that the duration of symptoms was longer than two weeks in $69.35 \%$ of cases.

According to the size of the stones the patients were divided in to 3 groups: 5 up to $10 \mathrm{~mm}-$ $38(27.74 \%)$ patients, 10 up to15 $\mathrm{mm}-76(55.47 \%)$ and 15 up to $20 \mathrm{~mm}-23(16.79 \%$ ) cases (Table 2).

Table 2

Distribution of patients according to the stone localization and size

\begin{tabular}{|c|c|c|c|c|}
\hline \multirow{3}{*}{ Stone localization in the ureter } & \multicolumn{4}{|c|}{ Stone size, $\mathrm{mm}$} \\
\hline & \multirow{2}{*}{$\begin{array}{c}5-\text { up to } 10 \\
n(\%)\end{array}$} & \multirow{2}{*}{$\begin{array}{c}10-\text { up to } 15 \\
n(\%)\end{array}$} & \multirow{2}{*}{$\begin{array}{c}15-\text { up to } 20 \\
n(\%)\end{array}$} & \multirow{2}{*}{ Total, (\%) } \\
\hline & & & & \\
\hline Upper third & $14(18.4)$ & $44(57.9)$ & $18(23.7)$ & $76(55.5)$ \\
\hline Middle third & $3(20.0)$ & $12(80.0)$ & $0(0.0)$ & $15(10.9)$ \\
\hline Lower third & $21(45.7)$ & $20(43.5)$ & $5(10.9)$ & $46(33.6)$ \\
\hline Total, $(\%)$ & $38(27.7)$ & $76(55.5)$ & $23(16.8)$ & $137(100.0)$ \\
\hline
\end{tabular}

For the most part of patients $(55.5 \%)$ the stone were localized in the upper third of the ureter and in $55.5 \%$ cases the stone size was 10 up to $15 \mathrm{~mm}$.

Total amount of sessions of ESWL to patients with ureteral stones was 377 (in average $2.8 \pm 0.4$ /person).

The patients were given intravenous aneastesia (fentanil $50 \mathrm{mcg}$ ).

Unfortunately, all the patients did not achieve fragmentation, complete stone elimination or had complications so ureteroscopy as second line of treatment was performed.

The duration of common symptoms associated with ureterolithisis till URS was in the term $\leq 7$ days in $1(0.73 \%)$ case, $8-14$ days -8 (5.84 \%), 15-29 days - 47 (34.31\%), 30-59 days $49(35.77 \%), \geq 60$ days $-32(23.36 \%)$. 
Duration from hospitalization till URS was in average $11.14 \pm 4.46$ (from 2 up to 34 ). Average operation time was $35.77 \pm 12.77 \mathrm{~min}$. (from 10 up to $80 \mathrm{~min}$.).

In 135 patients, endoscopic removal of stones has been succeeded (130 patients during URS and 5 patients during antegrade PCNUL), in 2 patients because of total obliteration of the ureter, open surgery uretero-ureteral anastomosis has been performed.

We tried to identify the changes in the ureter in the location of the stone during URS to find out the probably reason of failure of ESWL (Table 3). Performing URS we also found that in $117(85.4 \%)$ patient's stones in the ureter were already fragmented after ESWL, in 20 (16.6 \%) cases the stone was undamaged.

Table 3

Changes in the ureter in the location of the stone identified during URS

\begin{tabular}{|c|c|c|c|c|c|c|}
\hline \multirow{3}{*}{ Changes in the ureter in the location of the stone } & \multicolumn{6}{|c|}{ Duration of symptoms before performing URS } \\
\hline & \multirow{2}{*}{$\begin{array}{c}\leq 7 \\
n(\%)\end{array}$} & \multirow{2}{*}{$\begin{array}{c}7-14 \\
n(\%)\end{array}$} & \multirow{2}{*}{$\begin{array}{l}15-29 \\
n(\%)\end{array}$} & \multirow{2}{*}{$\begin{array}{l}30-59 \\
n(\%)\end{array}$} & \multirow{2}{*}{$\begin{array}{l}\geq 60 \\
n(\%)\end{array}$} & \multirow{2}{*}{ Total, (\%) } \\
\hline & & & & & & \\
\hline Oedema of the ureteral wall mucosa & $1(1.0)$ & $8(7.8)$ & $41(40.2)$ & $40(39.2)$ & $12(11.8)$ & $102(74.5)$ \\
\hline Impacted stone & $0(0.0)$ & $0(0.0)$ & $1(6.3)$ & $3(18.8)$ & $12(75.0)$ & $16(11.7)$ \\
\hline Non-diagnostic stricture of the ureter & $0(0.0)$ & $0(0.0)$ & $3(21.4)$ & $5(35.7)$ & $6(42.9)$ & $14(10.2)$ \\
\hline $\begin{array}{l}\text { Obstruction of the ureter by the stone without any } \\
\text { morphological chances }\end{array}$ & $0(0.0)$ & $0(0.0)$ & $2(40.0)$ & $1(20.0)$ & $2(40.0)$ & $5(3.6)$ \\
\hline Total, $(\%)$ & $1(0.7)$ & $8(5.8)$ & $47(34.3)$ & $49(35.8)$ & $32(23.4)$ & $137(100.0)$ \\
\hline
\end{tabular}

In 118 cases because of inflammatory changes of the ureteral wall, pyelonephritis or postoperative rick of obstruction of the upper urinary tract the kidney was drained by double-JJ stent for a term of 2-4 weeks.

For prevention of infection complications or treatment of pyelonephritis patients were given antibiotics (cephalosporin III-IV generation) in dose 1 gram twice/day for 5-7 days during staying in the clinic.

The duration of hospitalization patients was $17.02 \pm 4.87$ days (from 5 up to 37), including term from hospitalization till URS $-11.28 \pm 4.56$ days (from 2 up to 34 ) and post-operation locating in the clinic $5.74 \pm 1.64$ days (from 2 up to 19).

Double-JJ stents, which have been installed during operation, were removed after $2-4$ weeks outpatient.

\section{Discussion}

In summary, we would like to note, that in the literature of last years there are only few number of studies, as well as our, where scientists tried to identificate the changes which appear in the ureter on the location of the stone. Some of them were bases on experiments on laboratory animals [18], some of them included real patients' endoscopic examination with video and histological studying $[19,20]$.

Our work gives the opportunity for practical urologist to discover new point of view on reasons of failure of extracorporeal shockwave lithotripsy, indicate on probable risk factors, which can decrease the effectiveness of low-invasive treatment of ureterolithiasis. As the result, this knowledge can increase the stone-free rate in patients with ureteral stones by making correct treatment prescriptions, decrease the cost of surgical interventions and term of post-operative supervision in the hospital saving financial resources of patients and domestic health.

Study limitations. The study did not include individuals with pregnancy, uncontrolled (active) urinary tract infections, arterial aneurysm of cyst in the vicinity of the stone, obstruction distal to the stone, skeletal malformations and obesity, which prevent targeting of the stone. Patients with bleeding disorders, which were not compensated for at least 24 hours before treatment were not involved in the study. 
Prospects for further research. Further studies of prognostic factors of inefficacy of low-invasive treatment (extracorporeal shockwave lithotripsy and ureterolithotripsy) of patients with ureterolithiasis and deeper morphological analyses of upper urinary tract changes should be conducted in order to increase the level of efficacy of surgical interventions.

\section{Conclusion}

The URS and ESWL are high effective and minimal invasive methods of surgical intervention for patients with ureterolithiasis, guaranteeing high level of postoperative «stone free rate».

In 135 (98.5\%) patients endoscopic removal of stones has been succeeded, in 2 patients because of total obliteration of the ureter, uretero-ureteral anastomosis has been performed. If the symptoms, with are characteristic of ureterolithiasis, persists up to one week, stones do not cause significant macroscopic changes to the ureter wall. If the stone persists in the ureter longer than a week local appearing of oedema is identified. Long-term (more than two months) ureteric stone persistence greatly increase the risk of intramucosal «ingrowth» of the calculi.

Changes in the ureter wall (oedema or intramucosal «ingrowth») in the location of the stone associated with the duration of the disease symptoms explain the reason of the failure (absence of elimination of stone fragments) after ESWL with a satisfactory level of fragmentation in $117(85.4 \%)$ cases accordion to the URS findings.

Prolongation of the stone insertion time in the ureter causes the ureteric wall changes, complicating performance of minimal invasive interventions (URS and ESWL) and reduce its efficacy.

\section{Conflict of interests}

The author has no conflict of interest to declare.

\section{Financing}

The study was performed without financial support.

\section{References}

[1] Sorokin, I., Mamoulakis, C., Miyazawa, K., Rodgers, A., Talati, J., Lotan, Y. (2017). Epidemiology of stone disease across the world. World Journal of Urology, 35(9), 1301-1320. doi: http://doi.org/10.1007/s00345-017-2008-6

[2] Worcester, E. M., Coe, F. L. (2010). Calcium Kidney Stones. New England Journal of Medicine, 363 (10), $954-963$. doi: http://doi.org/10.1056/nejmcp1001011

[3] Ray, A. A., Ghiculete, D., Pace, K. T., Honey, R. J. D. (2010). Limitations to Ultrasound in the Detection and Measurement of Urinary Tract Calculi. Urology, 76 (2), 295-300. doi: http://doi.org/10.1016/j.urology.2009.12.015

[4] Smith-Bindman, R., Aubin, C., Bailitz, J., Bengiamin, R. N., Camargo, C. A., Corbo, J. et. al. (2014). Ultrasonography versus Computed Tomography for Suspected Nephrolithiasis. New England Journal of Medicine, 371 (12), 1100-1110. doi: http://doi.org/10.1056/nejmoa1404446

[5] Heidenreich, A. (2002). Modern Approach of Diagnosis and Management of Acute Flank Pain: Review of All Imaging Modalities. European Urology, 41 (4), 351-362. doi: http://doi.org/10.1016/s0302-2838(02)00064-7

[6] Smith-Bindman, R., Moghadassi, M., Griffey, R. T., Camargo, C. A., Bailitz, J., Beland, M., Miglioretti, D. L. (2015). Computed Tomography Radiation Dose in Patients With Suspected Urolithiasis. JAMA Internal Medicine, 175 (8), $1413-1416$. doi: http://doi.org/10.1001/jamainternmed.2015.2697

[7] Rodger, F., Roditi, G., Aboumarzouk, O. M. (2018). Diagnostic Accuracy of Low and Ultra-Low Dose CT for Identification of Urinary Tract Stones: A Systematic Review. Urologia Internationalis, 100 (4), 375-385. doi: http://doi.org/10.1159/ 000488062

[8] Xiang, H., Chan, M., Brown, V., Huo, Y. R., Chan, L., Ridley, L. (2017). Systematic review and meta-analysis of the diagnostic accuracy of low-dose computed tomography of the kidneys, ureters and bladder for urolithiasis. Journal of Medical Imaging and Radiation Oncology, 61 (5), 582-590. doi: http://doi.org/10.1111/1754-9485.12587

[9] Türk, C., Neisius, A., Petrik, A., Seitz, C., Skolarikos, A., Thomas, K. (2020). EAU Guidelines on Urolithiasis. Netherlands: EAU Guidelines Office. Available at: https://uroweb.org/wp-content/uploads/EAU-Guidelines-on-Urolithiasis-2020.pdf

[10] Turk, C., Knoll, T., Petrik, A., Sarica, K., Skolarios, A., Straub, M. (2015). Guidelines on Urolithiasis. Netherlands: EAU Guidelines Office. Available from: https:/uroweb.org/wp-content/uploads/22-Urolithiasis_LR_full.pdf 
[11] Iqbal, N., Malik, Y., Nadeem, U., Khalid, M. et. al. (2018). Comparison of ureteroscopic pneumatic lithotripsy and extracorporeal shock wave lithotripsy for the management of proximal ureteral stones: A single center experience. Türk Üroloji Dergisi/ Turkish Journal of Urology, 44 (3), 221-227. doi: http://doi.org/10.5152/tud.2018.41848

[12] Cui, Y., Cao, W., Shen, H., Xie, J., Adams, T. S., Zhang, Y., Shao, Q. (2014). Comparison of ESWL and Ureteroscopic Holmium Laser lithotripsy in Management of Ureteral Stones. PLoS ONE, 9 (2), e87634. doi: http://doi.org/10.1371/journal.pone.0087634

[13] Dell'atti, L., Papa, S. (2016). Ten-year experience in the management of distal ureteral stones greater than $10 \mathrm{~mm}$ in size. Il Giornali Di Chirurgia, 37 (1), 27-30. doi: http://doi.org/10.11138/gchir/2016.37.1.027

[14] Sagalevich, A. I., Vozianov, O. S., Ozhohin, V. V., Dzhuran, B. V., Kogut, V. V., Gaysenyuk, F. Z., Sergiychuk, R. V. (2018). Treatment of ureterolithiasis with the use of percutaneous antegrade ureterolithotripsy. Zaporozhye Medical Journal, 22 (2), 162-166. doi: http://doi.org/10.14739/2310-1210.2018.02.124838

[15] Choi, J. D., Seo, S. I., Kwon, J., Kim, B. S. (2019). Laparoscopic Ureterolithotomy vs Ureteroscopic Lithotripsy for Large Ureteral Stones. JSLS : Journal of the Society of Laparoendoscopic Surgeons, 23 (2), e2019.00008. doi: http://doi.org/10.4293/ jsls.2019.00008

[16] Torricelli, F. C. M., Monga, M., Marchini, G. S., Srougi, M., Nahas, W. C., Mazzucchi, E. (2016). Semi-rigid ureteroscopic lithotripsy versus laparoscopic ureterolithotomy for large upper ureteral stones: a meta - analysis of randomized controlled trials. International Braz j Urol, 42 (4), 645-654. doi: http://doi.org/10.1590/s1677-5538.ibju.2015.0696

[17] Şahin, S., Aras, B., Ekşi, M., Şener, N. C., Tugču, V. (2016). Laparoscopic Ureterolithotomy. JSLS : Journal of the Society of Laparoendoscopic Surgeons, 20 (1), e2016.00004. doi: http://doi.org/10.4293/jsls.2016.00004

[18] Lesovoy, V. N., Yakovtova, I. I., Danilyuk, S. V., Stetsishin, R. V. (2018). Morphofunctional state of the ureter wall in the experimental modeling of uretherolithiasis. Urology, 21 (1), 22-27. doi: http://doi.org/10.26641/2307-5279.21.1.2017.150084

[19] Vogt, B., Chokri, I. (2020). Histological Inflammation in Human Ureter either Healthy or Fitted with Double-Pigtail Stent or a Thin 0.3 F Suture Thread: A Preliminary Study. Advances in Urology, 2020, 1-5. doi: http://doi.org/10.1155/2020/1204897

[20] Hamamoto, S., Okada, S., Inoue, T., Sugino, T., Unno, R., Taguchi, K. et. al. (2020). Prospective evaluation and classification of endoscopic findings for ureteral calculi. Scientific Reports, 10 (1). doi: http://doi.org/10.1038/s41598-020-69158-w

How to cite: Vozianov, O. (2021). The reasons of unsatisfactory results of extracorporeal shock wave lithotripsy in patients with ureterolithiasis. EUREKA: Health Sciences, 4, 48-53. doi: http://doi.org/10.21303/2504-5679.2021.001797 